\title{
ADEQUACY OF CURRENT AND FUTURE INCOME AND ASSETS AND THE RISK OF MORTALITY IN A COHORT OF OLDER MEN - THE MANITOBA FOLLOW-UP STUDY
}

\author{
P.D. St John ${ }^{1,2}$, R.B. Tate Ta, $^{2}$
}

\begin{abstract}
Background: Income security is a determinant of health in most populations, but there is less evidence in very old men. Objective: To determine if self-reported current income adequacy or future expectation of income adequacy predicts death amongst older men. Design and Setting: We conducted an analysis of a prospective cohort of 3983 men who have been followed since 1948. In 2006, 1001 men were alive, of whom 807 completed the annual survey without assistance. Two items in the 2006 survey were: "How well do you think your income and assets satisfy your current needs?" and "How well do you think your income and assets will satisfy your needs in the future?" We considered the categories: "very adequate, adequate and inadequate." Time to death over the next 11 years was examined with the Cox proportional hazards models, and adjusted for age, marital status, and functional status. Results: The mean age in 2006 was 85 years old. The median follow-up time was 6.1 years, and 664 of the participants died. Satisfaction with current income did not predict mortality. Those with an expectation of inadequate future income had a higher risk of death: Hazard Ratio of 1.37 [(95\% CI $) 1.02,1.84)]$ for "Not adequate" relative to "Very Adequate". In models adjusted for age, marital status and functional status, this association was only marginally statistically significant ( $\mathrm{p}=0.07$ ). Conclusions: Perceived adequacy of future income predicts mortality in very old men. The effect may be confounded or mediated by functional decline.
\end{abstract}

Key words: Social position, satisfaction with income adequacy, aging, men, mortality.

\section{Introduction}

Social and economic circumstances have long been noted to predict adverse health outcomes in general populations (1-3). More recently, education and income security have been further studied in older populations (4-6). While the effect of social position on health appears to diminish or reverse in late life compared to early life $(7,8)$, measures of social position predict mortality (9), disability (9), multimorbidity (10) and healthy ageing (11) even in older populations. Social determinants of health, such as income, education and occupation, are potentially modifiable risk factors for adverse outcomes. Some social determinants of health which are generally well defined in early life, such as educational attainment, may be difficult to modify in very late life. However,

1. Section of Geriatric Medicine, Max Rady College of Medicine, Rady Faculty of Health Sciences, University of Manitoba, Winnipeg, Canada; 2. Centre on Aging, University of Manitoba, Winnipeg, Canada; 3 . Department of Community Health Sciences, Max Rady College of Medicine, Rady Faculty of Health Sciences, Winnipeg, Canada

Corresponding Author: Philip D St John, MD, MPH, FRCPC, Professor, Section of Geriatric Medicine, Max Rady College of Medicine - University of Manitoba - Room GE547 Health Sciences Centre, 820 Sherbrook St, Winnipeg R3A 1R9, Phone 204-787-1819, Email: pstjohn@hsc.mb.ca, other determinants, such as maintaining income security, may be more amenable to intervention at all stages in the life course. Efforts to secure stable pensions, support low income individuals, and maintain access to social services may serve to improve health in late life, and reduce health inequalities even into late life (12).

In Canada, income support to older persons is provided from various sources. A small percentage of older Canadians remain employed, and continue to have a work-related income. Others rely primarily on savings and investments. However, most older adults receive a pension - some through their employment, and some through the Canada Pension Plan (CPP) or Quebec Pension Plan (QPP). Almost all individuals who work in Canada and Quebec contribute to the CPP or QPP while working, and are then eligible for CPP/QPP pensions. The monthly pension is dependent upon the duration of employment as well as employment income. In addition, all Canadians receive the Old Age Security (OAS) pension. This is funded out of the general revenues of the Government of Canada, and is available to all residents over the age of 65 . For low income older adults, a Guaranteed Income Supplement (GIS) is also available to ensure that a basic income is met (13). While poverty remains a substantial concern amongst older Canadians 
(14), the poverty rates are comparable to OECD countries $(15,16)$. Poverty rates are considerably higher among older women than older men in Canada.

While there is compelling evidence that income security remains a social determinant of health in working age populations, there is less evidence in very old populations. Furthermore, the effect may differ between societies. A recent review notes the importance of maintaining income security in older populations, but calls for ongoing study of the effect of income security on late life health, since the effect may vary across time intervals or across societies (4). Another issue is the measurement of social position in late life. There are numerous aspects of social and economic position educational attainment, income, total wealth, as well as measures of income adequacy - and they may predict adverse outcomes differently. Furthermore, different measures of income adequacy may measure income security in the present, or measure the expectation of income adequacy to meet future needs.

To address some of these issues, we explored selfassessed income and asset adequacy in an existing cohort of older men - the Manitoba Follow Up Study (MFUS). Specifically, the objectives are: 1 . To determine if selfassessed current income adequacy predicts death over a long (11 year) time interval; and 2 . To determine if selfassessed expectations of future income adequacy predict death over a long time interval.

\section{Methods}

The Manitoba Follow-up Study (MFUS) (17)is a prospective cohort study of cardiovascular disease and ageing. The MFUS cohort consists of 3983 men recruited from the Royal Canadian Air Force at the end of the Second World War. At entry to the study, 1 July 1948, their mean age was 31 years, with $90 \%$ between ages 20 and 39 years. All study members were free of clinical evidence of ischemic heart disease. The protocol of MFUS was to obtain routine medical examinations from these men at regular intervals over time. The research goal of the study was to examine the role that non-specific abnormalities detected on routine electrocardiograms from apparently healthy men might play in the prediction of subsequent diagnoses of cardiovascular disease. The research focus was expanded in 1996 to explore the roles of physical, mental and social functioning (18). In 2017, 180 were alive $(5 \%)$, with a mean age $96 y ; 91 \%$ lived in Canada, and 36\% developed IHD. The study receives annual approval from the University of Manitoba Health Research Ethics Board.

The study methods have been previously reported (17). The study protocol evolved with the ageing of the cohort. Initially, study members were contacted at 5-year intervals, then 3-year intervals, every year, twice a year and now three times each year. This annual medical contact queries if they had seen their primary care provider, or if they have been admitted to hospital during the past year. If they have, then the medical records are obtained. As well, records pertaining to the death of the participant are also received. These records are then reviewed by physicians who code the charts for disease states and cause of death. Over the seventy years of follow-up, there have been 22 participants who have been lost to follow-up (defined as having no contact during the previous three consecutive years). A Successful Aging Questionnaire (SAQ) was added in 1996 and repeated in 2002, 2004 and annually since then, with annual completion rates exceeding $80 \%$. Core components of the SAQ in all years have been: Living arrangements, marital status, items of social engagement, self-rated health, items of life satisfaction, the ability to perform basic and instrumental activities of daily living (ADL, IADL), and the Short Form -36 (SF-36). The SAQ is completed by the participant, or appropriate proxy. Participants who enter long term care do not complete the SAQ, but medical records continue to be reviewed. Items on income adequacy were added to the 2006 survey of MFUS These items were: "How well do you think your income and assets satisfy your current needs?" and "How well do you think your income and assets will satisfy your needs in the future?" The responses were recorded on five point ordinal scales. We collapsed categories into very adequate (very well); adequate (adequately); and not adequate (with some difficulty; not very well; totally inadequate); since there were very few individuals with low income satisfaction.

We defined the observation window for this analysis to be from the date of return of the Spring 2006 survey to December 31, 2017, a follow up time of just over 11 years. We considered the outcome as the time to death. We created Kaplan - Meier survival curves for the time to death, and used log rank tests to determine differences in the survival probability across income adequacy categories. We then constructed Cox proportional hazards models with the time to death as the outcome. Other factors in the Cox models were marital status in 2006 (defined as married or not married), age, and the number of impairments in BADLs or IADLs, considered as continuous variables.

There were 1001 participants considered alive at the time of the 2006 mailing: 807 questionnaires were returned completed by the man; 34 were returned completed by a proxy; 54 were returned incomplete (due to death, illness, or relocated); 106 were not returned. There were 18 individuals who did not complete the item on adequacy of current income and 22 individuals who did not complete the item on adequacy of future income.

\section{Results}

There were 807 men considered in these analyses. Over a median follow-up time of 6.1 years to the end of 2017, $664(82 \%)$ of the men died. Most of the men 
Table 1

Baseline characteristics of the sample

\begin{tabular}{|c|c|c|c|c|}
\hline & \multicolumn{4}{|c|}{ Adequacy of Future Income } \\
\hline & Very Adequate $(\mathrm{N}=331)$ & Adequate $(\mathrm{N}=394)$ & Inadequate $(\mathrm{N}=60)$ & Total Sample $(\mathrm{N}=785)$ \\
\hline Age (mean years, SD) & $85.4(3.0)$ & $85.6(3.2)$ & $86.7(3.5)$ & $85.6(3.1)$ \\
\hline Marital Status (percent married) & $66 \%$ & $71 \%$ & $70 \%$ & $69.0 \%$ \\
\hline ADL impairment (mean, 0-7) & $0.6(1.6)$ & $0.7(1.5)$ & $1.2(2.6)$ & $0.7(1.7)$ \\
\hline IADL impairment (mean, 0-7) & $2.1(2.1)$ & $2.4(1.9)$ & $2.7(2.4)$ & $2.3(2.0)$ \\
\hline
\end{tabular}

ADL is activities of daily living; IADL is instrumental activities of daily living

had adequate or very adequate self-reported income. Baseline characteristics are shown in Table 1. Those who felt that their future income would be inadequate were more likely to have impairments in ADLs. In unadjusted analyses, current income satisfaction did not predict mortality over the eleven year time frame (Figure 1 and Table 2). However, low satisfaction with income and assets in the future did predict mortality over the eleven year period (Figure 2). This effect did not appear to be a gradient, but seemed limited to those who felt their income would be inadequate in the future. In models which adjusted for baseline functional status and marital status, expectation of future income inadequacy did not predict mortality. Lower functional status was a very strong predictor of dying. Being married was associated with a lower mortality (Table 3 ).

Table 2

Results of Cox Proportional Hazards Model for current income

\begin{tabular}{lcc}
\hline & HR $(\mathbf{9 5} \% \mathbf{C I})$ & HR (95\% CI) \\
\hline Current Income & Ref & Ref \\
Very Adequate & $1.04(0.89,1.22)$ & $0.94(0.80,1.11)$ \\
Adequate & $1.10(0.77,1.57)$ & $0.90(0.62,1.29)$ \\
Not Adequate & - & $1.10(1.07,1.12)$ \\
Age & - & $0.82(0.69,0.97)$ \\
Marital Status & - & $1.10(1.05,1.16)$ \\
ADL impairment & - & $1.15(1.09,1.20)$ \\
IADL impairment & - &
\end{tabular}

HR is Hazard Ratio; CI is confidence interval; ADL is activities of daily living; IADL is instrumental activities of daily living

\section{Discussion}

We have examined the effect of income security on mortality over a decade among very old men. We have found that most of the men were satisfied or very satisfied with their income, and their expected future income. Those who felt that their future income would not meet their needs had a higher risk of death than those who did not. This effect did not appear to have a gradient effect across the range, but seemed limited to those who did not anticipate an adequate future income. When adjusted for baseline functional status, this effect was no longer apparent. Our findings are broadly similar to a large literature documenting the importance of income security on health outcomes in younger populations. We continue to observe an effect of income security in late life on mortality. However, this effect may be confounded by impaired functional status. Perhaps there is a mediating effect, whereby those with lower income security become functionally impaired prior to dying.

\section{Figure 1}

Kaplan Meier Plot for those with Very Adequate (category 1), Adequate (category 2) and Inadequate (category 3) self-rated adequacy of current income

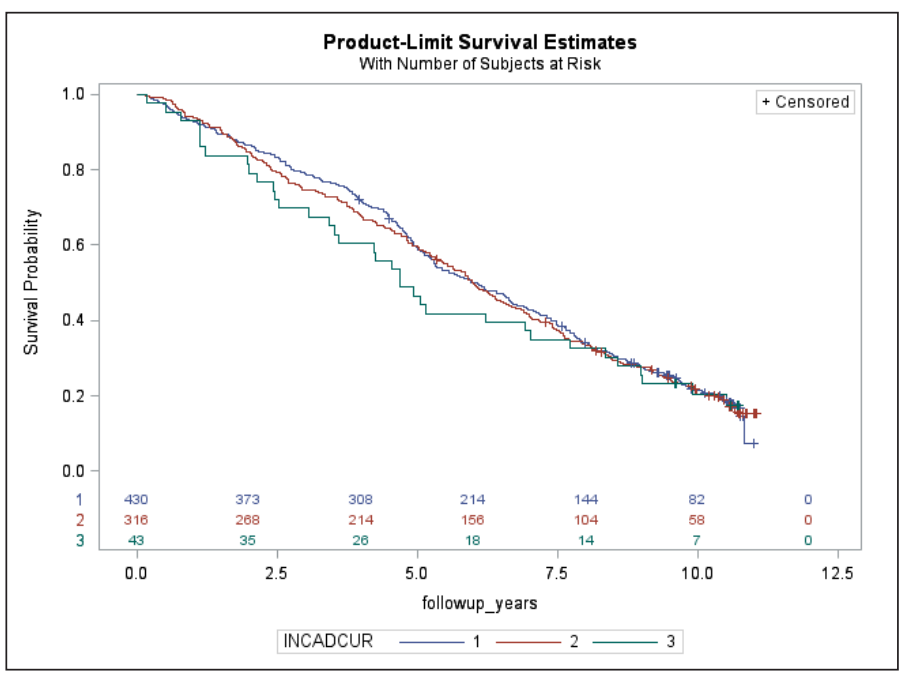

We also found that the majority of men were satisfied with their current and future expectation of income. To some extent, this reflects a success of Canadian pension policy - for men at least, most of whom were employed throughout their lives. This experience may not be shared by older women in Canada have higher rates of poverty and lower incomes than older men. It may also not be shared by older individuals in all countries. 


\section{Figure 2}

Kaplan Meier Plot for those with Very Adequate (category 1), Adequate (category 2) and Inadequate (category 3) self-rated adequacy of future income

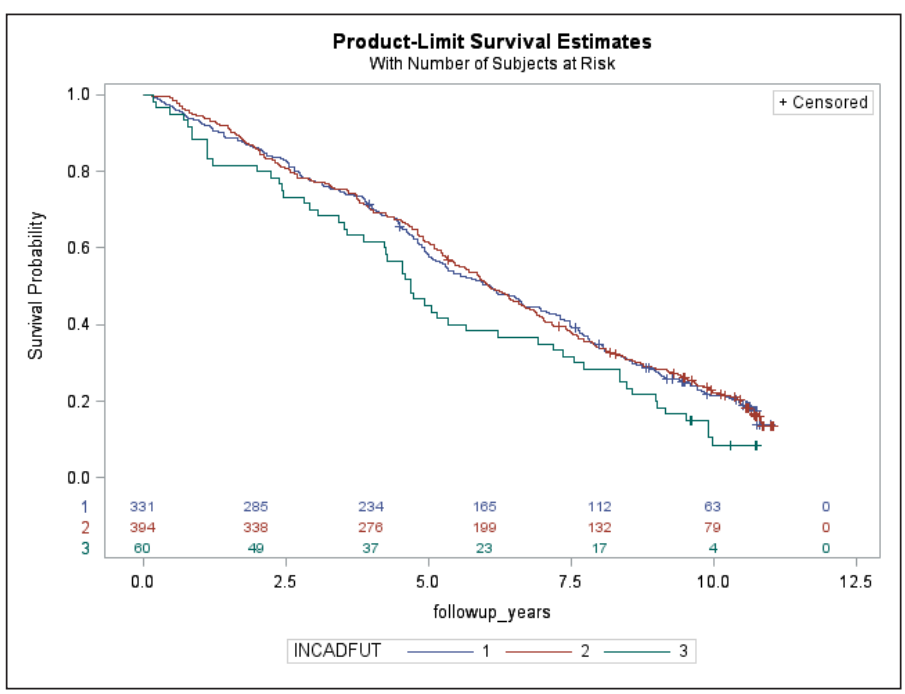

Table 3

Results of Cox Proportional Hazards Model for expected future income

\begin{tabular}{lcc}
\hline & HR $(\mathbf{9 5} \% \mathrm{CI})$ & HR $(\mathbf{9 5} \% \mathrm{CI})$ \\
\hline $\begin{array}{l}\text { Future Income } \\
\text { Very Adequate }\end{array}$ & Ref & Ref \\
Adequate & $1.00(0.85,1.18)$ & $0.90(0.77,1.07)$ \\
Not Adequate & $1.37(1.03,1.84)$ & $1.19(0.88,1.67)$ \\
Age & - & $1.09(1.06,1.12)$ \\
Marital Status & - & $0.81(0.69,0.96)$ \\
ADL impairment & - & $1.09(1.04,1.15)$ \\
IADL impairment & - & $1.15(1.10,1.21)$ \\
\hline
\end{tabular}

HR is Hazard Ratio; CI is confidence interval; ADL is activities of daily living; IADL is instrumental activities of daily living

There are strengths and limitations to our approach. First, we have a large population of very old men. There are few prospective cohort studies of men over the age of 85 . Second, the measure of income security we used is consistent with that used in other Canadian surveys. On the other hand, we considered subjective income security rather than the actual income. There is some debate about the merits of subjective assessments of social and economic security, although subjective measures of social position strongly predict health status and mortality in other cohort studies $(19,20)$. One advantage of subjective assessments is that they may be less sensitive to differences in the cost of living. Since this varies widely across Canada (where most of the participants reside), there are merits to these subjective measures. However, the use of these measures may limit the understanding of income effects on health for policy measures, where more objective measures of income may be needed. There are also limitations to the generalizability of our findings. The finding may not apply to those living outside Canada. However, the effects may be more apparent outside Canada, where rates of poverty are higher. Our findings also do not extend to women, where the rates of poverty are higher. Finally, the MFUS cohort members were all healthy at entry into the study, and had important shared life experiences, which limits the generalizability of our findings.

Nevertheless, if confirmed, our findings may have several implications. First, efforts to ensure income adequacy remain important even in late life. Others have found that mortality rate changes in England were linked to reductions in spending on income support for low income pensioners (21). Second, we did not observe a gradient effect. This should be verified in other studies. If true, then efforts to support low income older adults may be more important than redistribution of income across the spectrum of income, at least for mortalityrelated outcomes. Third, the effects of low income may be mediated through disability. Efforts aimed at restoring functional status may be relevant in low income men. Finally, there is a need for further study in other populations, particularly those with higher rates of income insecurity and in women.

Acknowledgements: The authors would like to thank (posthumously) Dr Francis Mathewson and Dr Ted Cuddy, previous directors of MFUS, and Dr Leon Michaels, Dr Julia Uhanova, and Dr Christie Macdonald (medical coders.) They would also like to thank the staff, past and present of the MFUS. Most importantly, they would also like to thank the participants of the study for the unwavering support throughout the years.

Financial support: These analyses were funded by the Canadian Institute for Health Research Project Grant Number PJT-152874. The Manitoba Follow-Up Study also received Bridge Funding from the Dean's Fund (Max Rady College of Medicine, University of Manitoba) and charitable donations from the participants and families of the Manitoba Follow-Up Study. The sponsors had no role in the design and conduct of the study; in the collection, analysis, and interpretation of data; in the preparation of the manuscript; or in the review or approval of the manuscript. The analyses and conclusions are the authors, and no endorsement from funding sources is implied.

Ethical standard: The Manitoba Follow-up Study receives annual approval from the Health Research Ethics Board of the University of Manitoba, and adheres to the Declaration of Helsinki.

\section{References}

1. Graunt J. Natural and Political Observations Made upon the Bills of Mortality London: Royal Society; 1662.

2. Mari-Dell'Olmo M, Gotsens M, Palencia L, Burstrom B, Corman D, Costa G et al. Socioeconomic inequalities in cause-specific mortality in 15 European cities. Journal of epidemiology and community health. 2015 May;69(5):432-41. PubMed PMID: 25631857. Epub 2015/01/30. eng.

3. Chetty R, Stepner M, Abraham S, Lin S, Scuderi B, Turner N, et al. The Association Between Income and Life Expectancy in the United States, 20012014. Jama. 2016 Apr 26;315(16):1750-66. PubMed PMID: 27063997. Pubmed Central PMCID: PMC4866586. Epub 2016/04/12. eng.

4. Huisman M, Read S, Towriss CA, Deeg DJ, Grundy E. Socioeconomic inequalities in mortality rates in old age in the World Health Organization Europe region. Epidemiologic reviews. 2013;35:84-97. PubMed PMID: 23382476. Epub 2013/02/06. eng.

5. Waldron H. Mortality differentials by lifetime earnings decile: implications for evaluations of proposed Social Security law changes. Social security bulletin. 2013;73(1):1-37. PubMed PMID: 23687740. Epub 2013/05/22. eng.

6. Hoffmann R. Socioeconomic inequalities in old-age mortality: A comparison of Denmark and the USA. Social Science \& Medicine. 2011 2011/06/01/;72(12):1986-92.

7. Liang J, Bennett J, Krause N, Kobayashi E, Kim H, Brown JW, et al. Old age 
mortality in Japan: does the socioeconomic gradient interact with gender and age? The journals of gerontology Series B, Psychological sciences and social sciences. 2002 Sep;57(5):S294-307. PubMed PMID: 12198109. Epub 2002/08/29. eng.

8. Merlo J, Gerdtham UG, Lynch J, Beckman A, Norlund A, Lithman T. Social inequalities in health- do they diminish with age? Revisiting the question in Sweden 1999. International journal for equity in health. 2003 Mar 11;2(1):2. PubMed PMID: 12685938. Pubmed Central PMCID: PMC153479. Epub 2003/04/11. eng.

9. Makaroun LK, Brown RT, Diaz-Ramirez LG, Ahalt C, Boscardin WJ, LangBrown S, et al. Wealth-Associated Disparities in Death and Disability in the United States and England. JAMA internal medicine. 2017 Dec 1;177(12):174553. PubMed PMID: 29059279. Pubmed Central PMCID: PMC5820733. Epub 2017/10/24. eng.

10. St John PD, Tyas SL, Menec V, Tate R. Multimorbidity, disability, and mortality in community-dwelling older adults. Canadian family physician Medecin de famille canadien. 2014 May;60(5):e272-80. PubMed PMID: 24829022. Pubmed Central PMCID: PMC4020665. Epub 2014/05/16. eng.

11. White CM, St John PD, Cheverie MR, Iraniparast M, Tyas SL. The role of income and occupation in the association of education with healthy aging: results from a population-based, prospective cohort study. BMC public health. 2015 Nov 25;15:1181. PubMed PMID: 26607694. Pubmed Central PMCID: PMC4660771. Epub 2015/11/27. eng.

12. Arno PS, House JS, Viola D, Schechter C. Social security and mortality: the role of income support policies and population health in the United States. Journal of public health policy. 2011 May;32(2):234-50. PubMed PMID 21326333. Pubmed Central PMCID: PMC3148579. Epub 2011/02/18. eng.

13. Statistics Canada. [April 2, 2018]. Available from: https://www.statcan. gc.ca/pub/11-630-x/11-630-x2016008-eng.htm.
14. Report of the National Seniors Council on Low Income Among Seniors. Ottawa 2009

15. Conference Board of Canada [April , 2018]. Available from: http:// www.conferenceboard.ca/hcp/Details / society / elderly-poverty. aspx?AspxAutoDetectCookieSupport=1.

16. OECD; [June 20, 2018]. Available from: https://data.oecd.org/inequality/ poverty-rate.htm

17. Tate RB, Cuddy TE, Mathewson FA. Cohort Profile: The Manitoba Follow-up Study (MFUS). International journal of epidemiology. 2015 Oct;44(5):1528-36. PubMed PMID: 25064641. Epub 2014/07/30. eng.

18. Swift AU, Tate RB. Themes from older men's lay definitions of successful aging as indicators of primary and secondary control beliefs over time: The Manitoba Follow-up Study. Journal of aging studies. 2013 Dec;27(4):410-8. PubMed PMID: 24300061. Epub 2013/12/05. eng.

19. Demakakos P, Biddulph JP, de Oliveira C, Tsakos G, Marmot MG. Subjective social status and mortality: the English Longitudinal Study of Ageing. European journal of epidemiology. 2018 May 19. PubMed PMID: 29779203. Epub 2018/05/21. eng.

20. Demakakos P, Nazroo J, Breeze E, Marmot M. Socioeconomic status and health: the role of subjective social status. Social science \& medicine (1982) 2008 Jul;67(2):330-40. PubMed PMID: 18440111. Pubmed Central PMCID: PMC2547480. Epub 2008/04/29. eng.

21. Loopstra R, McKee M, Katikireddi SV, Taylor-Robinson D, Barr B, Stuckler D. Austerity and old-age mortality in England: a longitudinal cross-local area analysis, 2007-2013. Journal of the Royal Society of Medicine. 2016 Mar;109(3):109-16. PubMed PMID: 26980412. Pubmed Central PMCID PMC4794969. Epub 2016/03/17. eng. 